\title{
Binding Set Analysis for Interaction of Human Serum Albumin with Cethyl Trimethylammonium Bromide
}

\author{
Abdol-Khalegh Bordbar, Nasrin Sohrabi, and Hossain Gharibi ${ }^{\dagger}$ \\ Deparment of Chemistrv. Isfahan University. Isfahan 81746-734+1, Iran \\ ${ }^{\dagger}$ Department of Chemistry, Tarbiat-Modares Cniversin, Tehran, Iran \\ Received Februarv 20.2004
}

\begin{abstract}
The binding of cethyl trimethylammonium bromide. (CTAB) with human senum albumin (HSA) has been investigated at $5 \mathrm{mM}$ phosphate buffer $\mathrm{pH} 7.0 .27^{\circ} \mathrm{C}$ and various ionic strength using ion selective membrane electrodes. This method is faster and mich more accurate than equilibrium dialy'sis technique. so provides sufficient and accurate data for binding data analysis. A novel and simple method was introduced for resolution and characterization of binding sets on basis of binding capacity concept. The values of Hill binding parameters were estimated for each set and used for calculation of intrinsic binding affinity. The results interpreted on basis of nature of forces which interfered in the interaction and represent the existence of three and two binding sets for binding of $\mathrm{CTAB}$ at $10^{-4}$ and $10^{-3} \mathrm{M}$ of $\mathrm{NaBr}$. respectively
\end{abstract}

Key Words : Binding capacity. Scatchard plot. Ionic surfactant. Huntan serum albunuin

\section{Introduction}

Human serum albumin (HSA) is the highly water-soluble plasma protein which is the smallest and most abundant plasma protein in the human body. accounting for $55 \%$ of the total protein in blood plasma. HSA is a single-stranded polypeptide whose amino acid sequence is known. ${ }^{1}$ Its ionizable groups include 116 total acidic groups (98 carboxyl and 18 phenolic-OH) and 100 total basic groups $(60$ amino. 16 imidazolyl. 24 guanidyl). The absolute molecular weight of $66436 \mathrm{D}$ was calculated from the numbers and molar masses of the consistent amino acid residues. which yields a contour length of the denatured protein of $\mathrm{L}$ contour(HSA) $=216 \mathrm{~nm}$ (as calculated from the number of residues and a peptide bond length of $0.37 \mathrm{~nm}$ ). HSA contains 17 disulfide bridges. One free thiol(cys 34) and a single tryptophan typically bind $1-2$ fatty acids per protein. : which effectively reduces the isoelectric point in $0.15 \mathrm{M}$ $\mathrm{NaCl}$. the $\mathrm{pI}$ for lipid-bound HSA is $4.7,3$ while $\mathrm{pI}=5.7$ for defatted $\mathrm{HSA}^{+}$At pH 7.4, the shape of native $\mathrm{HSA}$ in solution is thought to be a prolate ellipsoid of revolution with major and minor axes. respectively, 12.0 and $2.7 \mathrm{~nm}^{5}$ or 14.1 and $4.1 \mathrm{~nm} .{ }^{6.7}$ linking three homologous, globular domains in series.

Interaction between ionic surfactants and globular proteins has been extensively studied as the ligand binding affinities. ${ }^{8 . \overline{5}}$ It is important for understanding the stabilization of membranes. food enulsions and foams that the interactions between the protein and surfactant which leads to the formation of such complexes are characterized. ${ }^{10}$ Surfactants can be broadly divided into those which bind and initiate protein unfolding. i.e. denaturating surfactants. and those that only bind leaving the tertiary structure of the protein

\footnotetext{
Corresponding Author. Tel: +98-311-7932710; Fax: +98-311-
} 6689732: e-mail: bordbarấsci.ui.ac.ir intact. Commonly used anionic surfactants. such as sodium n-dodecyl sulfate (SDS). generally denature proteins where as non-ionic surfactants do not. ${ }^{11.12}$

The binding data for ionic surfactant-protein interaction can be measure experimentally. using equilibrium dialy $\operatorname{sis}^{13}$ and potentiometric tecluniques. ${ }^{14}$ Binding data analysis can reveal some important features of binding mechanism. However, different models of analysis that depend on various features of the binding process are required for this purpose. A number of methods for graphical and computerassisted analysis of the binding data for surfactant-protein interaction have been employed ${ }^{13.15 .16}$ One of the most common presentations of such data is the Scatchard plot. ${ }^{17}$ However, there is not a general and comprehensive method for characterization of binding sets in surfactant-protein system.

In the present study. the interaction of cethyl trimethylammonium bromide (CTAB) with HSA has been studied using ion selective membrane electrode as a fast and accurate teclunique. A novel graphical method has been introduced for binding data treatment and the results have been interpreted on basis of binding mechanism and leads to the formation of CTAB-HSA complexes are characterized.

\section{Materials and Method}

HSA (free fatty acid fraction $\mathrm{V}$ ) and CTAB were purchased from Signa Chemical Co. Tetralydrofurane (THF). acetone, nitric acid $(65 \%)$. sodium hydroxide, sodium bromide, panta oxide diphosphor $\left(\mathrm{P}_{2} \mathrm{O}_{5}\right)$. ethanol. carboxylated $\mathrm{PVC}$, high molecular weight. sodium phosphate and sodium hydrogen phosphate were obtained from Merck Chemical $\mathrm{Co}$. Silver wire and sodium reference electrode (serial num. 6.0501 100) were purchased from Metrohm Co. All the materials have high degree of purity. All of the solutions were prepared by double distilled water. The $5 \mathrm{mM}$ phosphate 


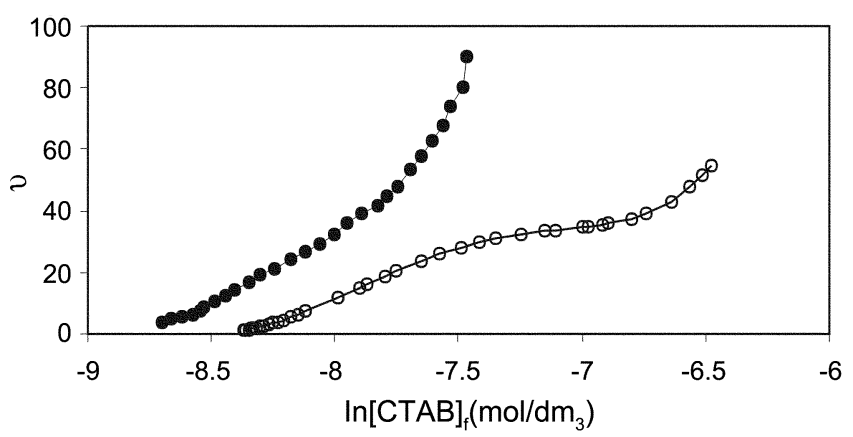

Figure 1. The binding isolherms for interaction of ClABs with IISA at pl I=7.0.5 m.M phosphate butfer and $27^{\circ} \mathrm{C}$. (O) $10^{\circ} \mathrm{M}$ and (;) $10^{-1} \mathrm{M}$ of $\mathrm{NaBr}$.

buffer $\mathrm{pH} 7.0$ was used as buffer. The HSA solutions were freshly prepared and used. For all the potentiometric measurements we used potentiometer of Metrohm model. 744.

Potentiometry. Free CTAB concentration was determined by means of a CTAB-selective plastic membrane electrode which has been reported to have an excellent CTAB selectivity and a Nernstian response. ${ }^{1 \cdot 1}$ The reference electrode was sodium electrode.

Binding data analysis and results. Figure 1 is the binding isotherms for interaction of CTAB with HSA and shows the variation of $v$ (the average number of bound CTAB per HSA molecule)versus $\operatorname{In}[\mathrm{CTAB}]_{\text {. }}$. The corresponding Scatchard plots for these isotherms are shown in Figure 2. These are not coincidence with usual shapes of Scatchard plots and can be represent the existence of more than one binding set. However, the resolution and characterization of binding sets is difficult through these plots. For overcoming to this deficiency, one can use the concept of binding capacity. Binding capacity is the homotropic second derivative of the binding potential with respect to the chemical potential of the ligand $\left(\mu_{\mathrm{s}}\right)$ and provides a measure of steepness of the binding isotherm. ${ }^{18}$ It represents the changes in the number of mole of ligand per mole of the macromolecule ( $v$ ) that accompanies a change in the chemical potential of that ligand. The heat capacity and the compressibility define analogous concepts with respect to temperature and pressure, respectively. By considering the

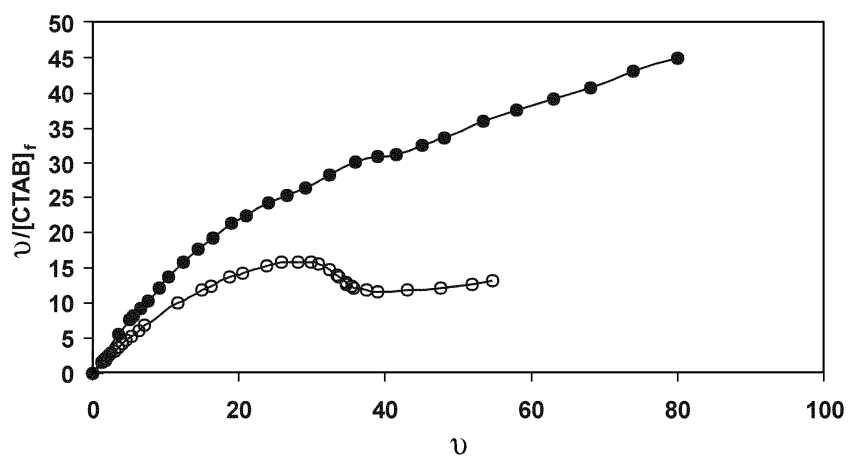

Figure 2. The Scatchard plots for interaction of C'IAB with IISA at $\mathrm{pH}=7.0 .5 \mathrm{mM}$ phosphate buffer and $27{ }^{\circ} \mathrm{C} .(\bullet) 10{ }^{3} \mathrm{M}$ and $(\mathrm{C})$ $10^{-+} \mathrm{M}$ of $\mathrm{NaBr}$. ideal behavior $\left(\mu_{\mathrm{s}}=\mu_{\mathrm{a}}^{0}-R T \ln [S]_{f}\right)$, binding capacity $(\theta)$ equals to:

$$
\theta=\left(\frac{\partial v}{\partial \mu_{S}}\right)_{T, H_{i}, H_{i=c}}=\left(\frac{\partial v}{R T \partial \ln [S]_{f}}\right)_{T, \mu_{i=*}}
$$

Where $[S]$, is the free concentration of the ligand. This concept is directly related to the type and the extent of cooperativity. ${ }^{18}$ This parameter can be measured directly by using experimental techniques for some systems such as binding of oxygen to hemoglobin. ${ }^{19}$ However, using computer program for fitting of the binding isotherms in an appropriate equation and then calculating the slope of binding isotherm through fitting equation, the values of $\theta$ at any $v$ can be determined.

It can be written for system with $\mathrm{N}$-independent binding sets:

$$
v-\sum_{s=1}^{x} v_{r} \text { and }\left(\frac{\partial v}{\partial v_{1}}\right)-1
$$

Where $v_{\mathrm{i}}$ is the average number of bound ligand in the ith binding set per macromolecule. With respect to equation (1). $\theta$ of this system is as follows :

$$
\theta=\frac{\partial v}{R T \partial \ln [S]_{t}}=\sum_{i-1}^{n}\left(\frac{\partial v_{i}}{R T \partial \ln \mid S]_{i}}\right)=\sum_{i-1}^{n} \theta_{i}
$$

Where $\theta_{1}$ is the contribution of the ith binding set in overall binding capacity. The Hill equation of this system is ${ }^{21) .21}$

$$
v=\sum_{i}^{N} \frac{g_{i}\left(K_{i}[S]_{f}\right)^{n_{W}}}{\left(1-\left(K_{i}[S]_{i}\right)^{n_{i j !}}\right)}
$$

Where $g_{i} K_{r}$ and $n_{H s}$ are the number of binding sites, binding constant and Hill coefficient for ith binding set, respectively. Using equations (1) and (4), it can be written :

$$
\theta_{i}-\frac{n_{t / s} v_{i}\left(g_{i}-v_{t}\right)}{g_{i} R T}
$$

With respect to equation (3) and (5), the binding capacity curve should be the summation of $\mathrm{N}$-Gaussian curve that each of them relates to the corresponding binding set. If $K_{r} \gg K_{i-1}$, it can be shown that this curve consists of $\mathrm{N}$ distinctive and consecutive maxima, that their positions determine the stoichiometry of binding sets (see $\Lambda$ ppendix).

This conclusion was obtained by considering of these assumptions.

1) $n_{H_{t}}$ is constant and 2) the binding sets are independent. These assumptions are usually reasonable for surfactantprotein system. However, the deconvolution of the peaks is still a dillicult problem.

For overcoming to it, equation (5) is rearranged as follows:

$$
R T \theta_{i} / v_{i}-n_{H i}-n_{H i} v_{i} / g_{i}
$$

For a system with one set of binding sites, it can be suggested that the curve of $[\mathrm{R} \mid \theta \cdot v]$ versus $v$ should be linear, where the slope, $\mathrm{Y}$ and $\mathrm{X}$-intercepts are $-n_{/ /} g, n_{H}$ and 


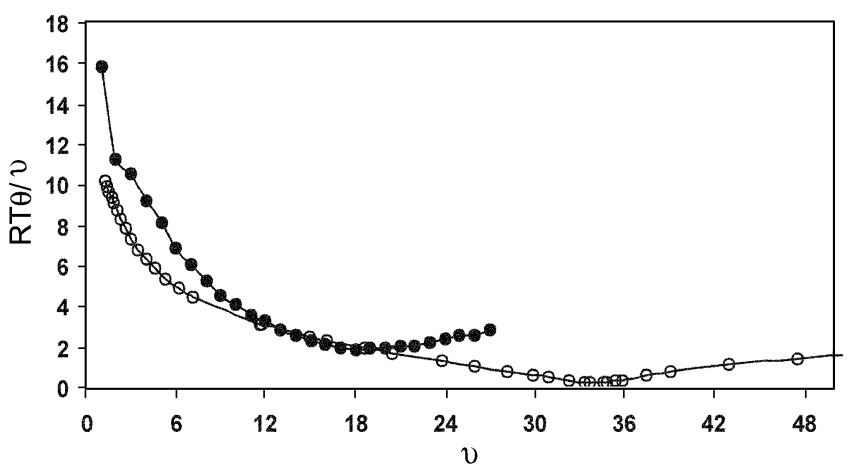

Figure 3. The plots of [RT $\theta: v]$ versus $v$ tor binding of CTAB wilh I ISA at pl I=7.0.5 m.M phosphate buller and $27^{\circ} \mathrm{C}$. ( ) $10^{\circ} \mathrm{M}$ and ( $\therefore$ ) $10^{-4} \mathrm{M}$ of $\mathrm{NaBr}$.

g, respectively. However, the shape of this curve for multiclasses of binding sites must be more complicated. The plots of [RT $\theta / v]$ versus $v$ for binding of CTAB to HSA are shown in Figure 3.

This curve can be divided to three and two linear parts which represents the existence of three and two binding sets
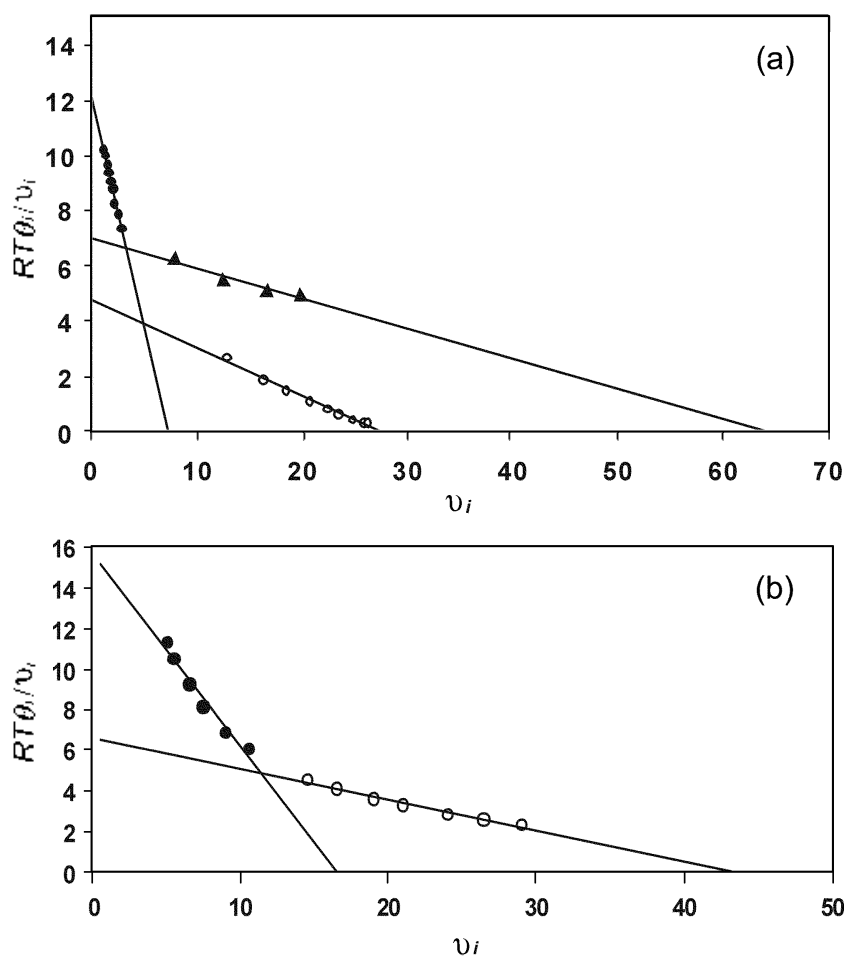

Figure 4. The variation of RT $\theta_{i} v_{i}$ versus $v_{\text {for }}$ forteraction of CTAB with HSA at pH 7.0.5 mM phosphate buller and $27^{\circ} \mathrm{C}$. (a) $[\mathrm{Nal} B \mathrm{r}]=10^{-4} \mathrm{M} .(\bullet)$ ) Jirst binding set. $(\mathrm{O})$ second binding set. ( $\Delta$ ) third binding set (b) $|\mathrm{NaBr}|=10^{-3} \mathrm{M}$. ( ) first binding set. (i) second hinding set.
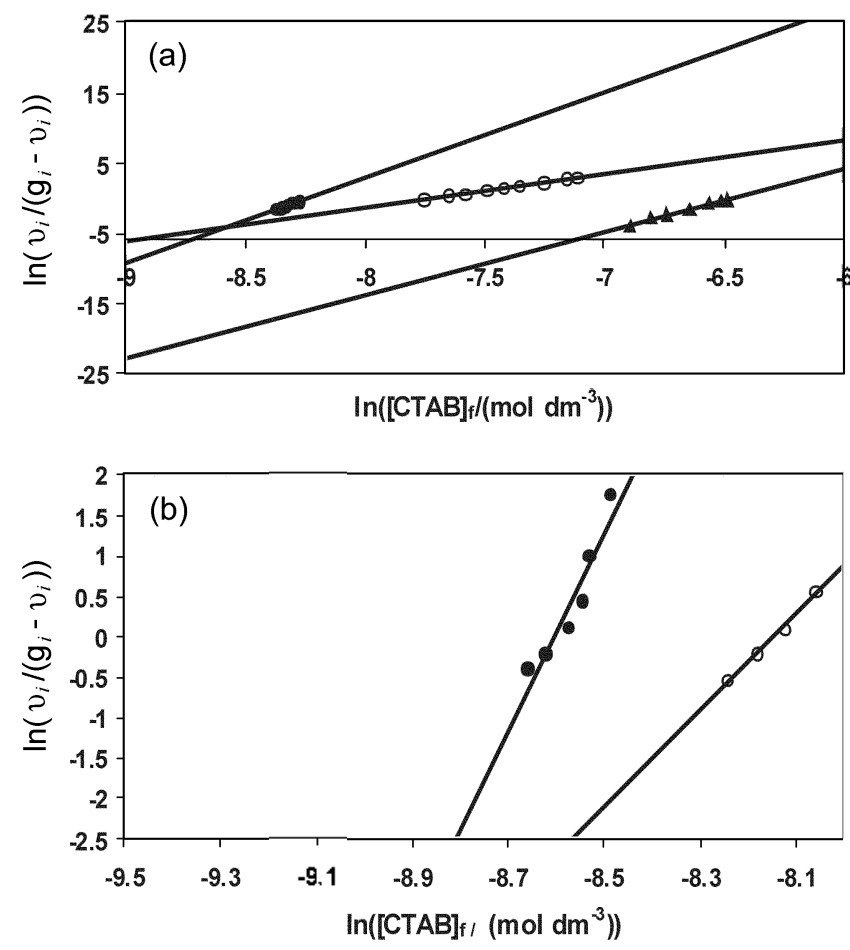

Figure 5. The Hill plots for interaction of CTAB with HSA at $\mathrm{pH} 7.0 .5 \mathrm{mM}$ phosphate buller and $27^{\circ} \mathrm{C}$. (a) $[\mathrm{NaBr}] 10^{-4} \mathrm{M}$. (-) first binding set. ( $)$ second binding sel, ( $\boldsymbol{\Delta}$ ) third binding set. (b) $[\mathrm{NaBr}]=10^{\circ} \mathrm{M}$. ( ) tirst binding set. (i) ) second binding set.

at $10^{-4}$ and $10^{-3} \mathrm{M}$ of $\mathrm{NaBr}$, respectively.

The number of binding sites of each set can be estimated from simple extrapolation of each linear part. Figure $4 a$ and $\mathrm{b}$ show the precise linear plots of RT $\theta / v$, versus $v_{i}$ for each set subsequently.

The slope of this curve is related to $n_{f \prime}$ with respect to equation (6). Knowing $n_{f i}$ and $g_{\text {o }}$ the Hill plots were constructed for estimation of Hill binding constant. $K_{i}$. Figure $5 \mathrm{a}$ and $\mathrm{b}$ show the corresponding Hill plots of each binding set, for interaction of CIAB with HSA at $10^{-4}$ and $10^{-7} \mathrm{M}$ of $\mathrm{NaBr}$, respectively. The high values of linear correlation coeffiecients of these lines confirm our binding data analysis. The collective values of Hill parameters were listed in Table 1.

The intrinsic Gibbs free energy of binding per mole of ClAB for ith binding set, $\Delta G^{(1)}{ }_{b . \psi}$, can be calculated by the following equation ${ }^{16}$ :

$$
\Delta G^{(h)}{ }_{r, r^{\prime}}-\mathrm{RT} n_{H} \ln K_{,}\left|\mathrm{RT}\left(1-n_{H}\right) \ln \right| \mathrm{CTAB} \mid r
$$

Figure $6 \mathrm{a}$ and $\mathrm{b}$ show the variation of $\Delta G^{(t)}$, versus $\ln [\mathrm{C} / \mathrm{AB}]$ for interaction of $\mathrm{C}$ IAB with $\mathrm{HSA}$ at $10^{-3}$ and $10^{-4} \mathrm{M}$ of $\mathrm{NaBr}$, respectively.

Table 1. The collective values of Hill parameters for interaction of $\mathrm{C}$ TAB with $\mathrm{HSA}$ at $\mathrm{pH}=7.0 .5 \mathrm{mM}$ phosphate buffer and 27 " $\mathrm{C}$.

\begin{tabular}{cccccccccc}
\hline$|\mathrm{Na13r}| \mathrm{M}$ & $n_{t / 1}$ & $g_{1}$ & $K_{1}\left(\mathrm{M}^{-1}\right)$ & $n_{I 2}$ & $g_{2}$ & $K_{2}\left(\mathrm{M}^{-1}\right)$ & $n_{t / 3}$ & $g_{3}$ & $K_{3}\left(\mathrm{M}^{-1}\right)$ \\
\hline $10^{-4}$ & 12.20 & 7.40 & $3.80 \cdot 10^{3}$ & 4.83 & 27.62 & $2.26 \cdot 10^{3}$ & 8.34 & 39.8 & $6.53 \times 10^{2}$ \\
$10^{3}$ & 12.00 & 12.3 & $5.47 \cdot 10^{3}$ & 5.96 & 31.70 & $3.48 \cdot 100^{3}$ & - & - & - \\
\hline
\end{tabular}



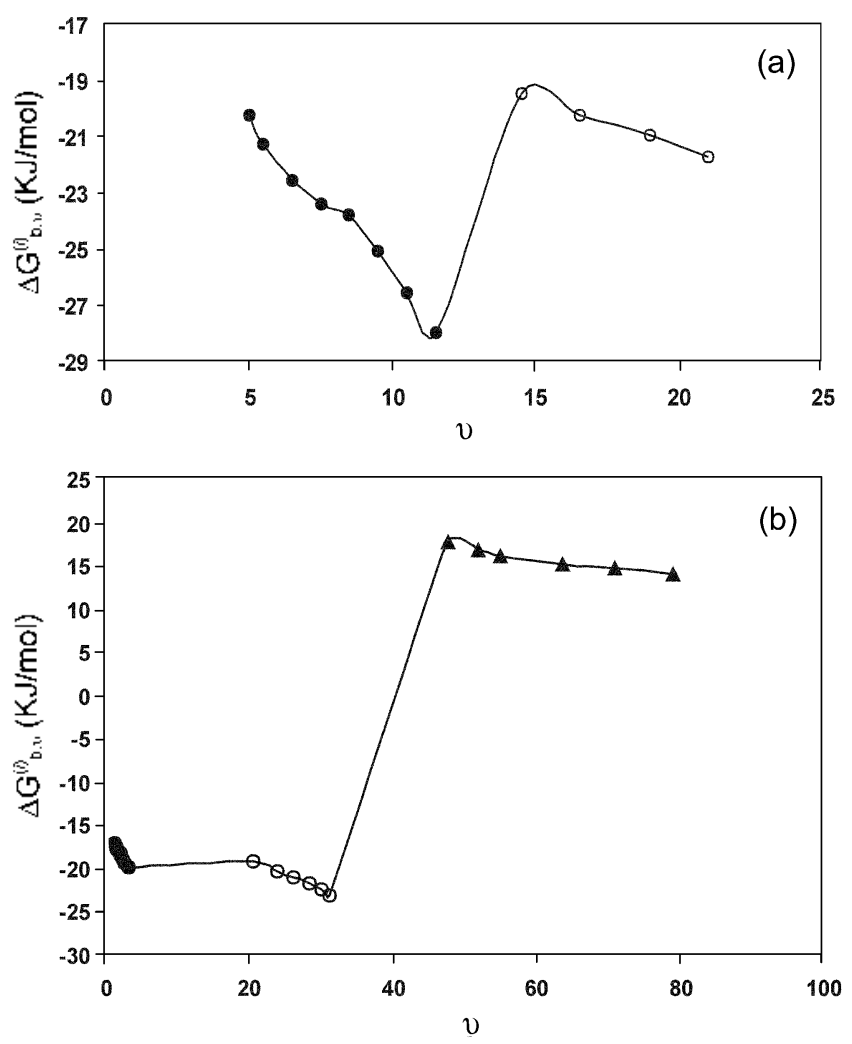

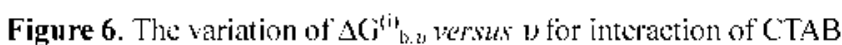
with HSA at $\mathrm{pH} \quad 7.0 .5 \mathrm{m.M}$ phosphate bulfer and $27^{\circ} \mathrm{C}$. (a) $[\mathrm{Nal} 3 \mathrm{r}]=10^{3} \mathrm{M} .10$ ) first binding sel. ( $s$ ) second binding sel. (b) $|\mathrm{NaBr}|=10^{-+} \mathrm{M} .(\bullet)$ ) first binding set. ( $(3)$ ) second binding set. (4) ) third binding set.

\section{Conclusion}

When the Scatchard analysis is applied to protein-surfactant interaction, examples of various kinds of cooperatively and unusual features were found. ${ }^{22.23}$ Although, the unusual feature of the Scatchard plot can be correlated to the existence of more than one binding set. the widespread misinterpretation and incorrect usage of non-linear Scatchard plots for surfactant-protein binding experiments are possible. ${ }^{24}$ This shortcoming arises from the similarity among the Scatchard plots for systems with various numbers of binding sets. Our proposed model on basis of binding capacity concept removed this shortcoming and determines the number of binding sets. Moreover, this method provides sufficient information for characterization of each binding set. The results for $\mathrm{HSA}-\mathrm{C}$. $\mathrm{ABB}$ interaction represent the existence of two and three binding sets at $10^{-3}$ and $10^{-4} \mathrm{M}$ of $\mathrm{NaBr}$, respectively. One mechanism of interaction for ionic surfactant-protein, could be the following: initial strong binding of surfactant jons, at low concentration, occurs to the ionic sites with opposite charge on the protein surface, this may, however, induce protein unfolding thus exposing many more hydrophobic binding sites previously buried in the core of tertiary structure. 1.35 Therefore, there are at least two binding sets in such systems. 'The first binding set was considered as electrostatic and the second hydrophobic.
However, the role of initial hydrophobic interaction in the first binding set has been generally accepted. This interpretation can be successfully applied for HSA-CTAB interaction at $10^{-3} \mathrm{M}$ of $\mathrm{NaBr}$. The positive cooperativity was observed in both binding sets which represents the special role of hydrophobic interactions. The three binding set behavior at $10^{-3} \mathrm{M}$ of $\mathrm{NaBr}$, can be related to the difference in binding affinity of various ionic binding sites on HSA at this condition. It is well known that HSA consist of three distinct domains in its folded structure that each carrying net charges of $-9 \mathrm{e}$ (domain I, N-terminal), $-8 \mathrm{e}$ (domain II) and -2e (domain III, C-terminal). ${ }^{2}$ Therefore, all of its negative charges have been located in domain $\mathrm{I}$ and $\mathrm{II}$. It is reasonable that each domain is taken as a distinct electrostatic binding set for interaction of CTAB with HSA.

Hence, the first two binding set at $10^{-1} \mathrm{M}$ of $\mathrm{NaBr}$ can be related to negative ionic charges in domain $I$ and $I I$, and the last to unfolded state of HSA and exposure of hydrophobic binding sites. This interpretation is confirmed by the little difference in binding affinity of first and second binding sets and relative high difference with third binding set (see Figure 6 ). The reduction of ionic interactions at $10^{-3} \mathrm{M}$ of $\mathrm{NaBr}$, caused the difference between binding affinity of these first two sets is reduced, so that both of them behaves as single binding set.

Acknowledgements. Financial supports of Center for Graduate Studies and Research Council of Isfahan University are gratefully acknowledged.

Appendix. If $K_{i-1}>K_{i}$, it means that the occupation of ith binding set is not been started until the saturation of $(i-1)$ th binding set. In the other word it can be written :

$$
\begin{array}{cc}
u=v_{1} \cdot \theta=\theta_{1} & \text { if } \quad v \leq g_{1} \\
u=g_{1}+v_{2}, \theta=\theta_{2} & \text { if } \quad g_{1}<v \leq\left(g_{1} \cdot g_{2}\right) \\
\vdots & \vdots \\
\vdots & \vdots \\
v=g_{1}-g_{2} \cdot \ldots+v_{j} \theta \theta=\theta_{t} \quad \text { if } \\
\left(g_{1}\left|g_{2}\right| \ldots g_{1}\right)<v \leq\left(g_{1}\left|g_{2}\right| \ldots g_{j}\right)
\end{array}
$$

With respect to equation (5). the derivative of $\theta$ versus $v$ is as bllows :

$$
\begin{aligned}
& \left(\frac{\partial \theta}{\partial v}\right)=\frac{n_{H 1}\left(g_{1}+2 v_{1}\right)}{R T g_{1}} \text { if } 0<v<g_{1} \\
& \left(\frac{\partial \theta}{\partial v}\right) \frac{n_{H_{2}}\left(g_{2}+2 v_{2}\right)}{R T g_{2}} \text { if } \quad g_{1}<v \leq\left(g_{1}-g_{3}\right) \\
& \left(\frac{\partial \theta}{\partial v}\right)=\frac{n_{t i s}\left(g_{r}+2 v_{1}\right)}{K / g_{i}} \text { if } \\
& \left(g_{1}+g_{2}+\ldots g_{i-1}\right)<v \leq\left(g_{1}-g_{2}+\ldots g_{1}\right)
\end{aligned}
$$




$$
\begin{aligned}
v_{\max .1}= & g_{1}: 2 \\
v_{\max .2}= & g_{1}-g_{2} 2 \\
& \cdot \\
& \cdot \\
v_{\max , t}= & g_{1}-g_{2}+\ldots g_{r} 2
\end{aligned}
$$

Hence, the binding curve for such system consists of $\mathrm{N}$ - consecutive masima that their positions determine the number of binding sites at each set.

\section{References}

1. Dayhotf. M. O. Athas of Protein Sequence and Stuchre: National Biomedical Foundation: Washington. DC. 1972.

2. Peters. T. All about Albmim. Biochemishy. Gemetics. and Medical Applications: Academic Press: New York 1992

3. Longworth. L. G.: Jacobsen. C. F. J. Phs. Colloid Chen. 1949. 53. 126 .

4. Gianazza. E:: Firgerio. A.: Astrua-Testori. S.: Righetti. P. G. Electrophoresis 1984. 5.310.

5. Haynes. C. A.: Norde. W. Coll. Surf. B: Biomterfaces 1994. 2. 517

6. Peters. T. Adt: Protein Chem. 1985, 37, 161.

7. Soderquist. M. E.: Walton A. G. J. Coll Int. Sci. 1980. 75. 386.

8. Goddard. E. D.: Ananthapadmanabhan. K. P. Interactions of Surfactants with Pohmers and Protems: CRC Press. Inc.: Florida. 1992: chapter 8 .

9. Tanford. C. The Hydrophobic Effect: Formation of Hicelles and
Biological Hembranes. 2nd ed: Wiley-Nescience: New York 1980: chapter 14

10. Jones. M. N. Brass. A. Food Polwners: Gels and Colloids: Pichinson. E., Ed.: Royal Society of Chemistry: Chambridge. 1991.

11. Vaslescu, M.: Angelescu, D.: Almgran. M: Valstar. A. Lamgmuir 1999. 15. 2635.

12. Nelsont. C. A. J. Biol. Chem 1971. 246(12). 3895.

13. Jones. M. N. Chemical Societu Review's 1992. 21. 127.

14. Gharibi. H.: Razavizadeh. B. M.: Rafati, A. A. Colloid Surfaces A: Phnsicochemical and Engineering Aspects 1998. 136, 123.

15. Jones. M. N. Biological Themodhamics: Jones, M. N.. Ed.: Elsevier: Amsterdam. 1988: $\mathrm{p} 182$.

16. Bordbar. A. K.: Saboury. A. A.: Housaindokltt. M. R.: MoosaviMovahedi. A. A.J. Coll. Int. Sci. 1997. 192. 415.

17. Scatchard, G. Am New York Acad Sci. 1949, 51,660.

18. Cera. E.: Gill, S.: Wyman. J. Proc. Kotl Acad Sci. US. 1988, 85. 449 .

19. Dolman1. D.: Gill. S. J. Anal Biochem 1978.87. 127.

20. Hill. A. V. J. Phusiol 1910. 40. 4.

21. Tanford. C. Phusical Chemisty of Macromolecules: Wiley: New York. 1961; chapter 9.

22. Moosavi-Movahedi, A. A.; Housaindokht, M. R. Int J. Biol. Macrontol. 1991, 13, 50

23. Housaindokht. M. R.: Chamanii. J.: Saboury. A. A.: MoosaviMovahedi. A. A.: Bahrololoom. M. Bull. Konam Chem. Soc 2001. 22. 145

24. Bordbar. A. K, Saboury, A. A.: Moosavi-Movahedi. A. A Biochem. Edu 1996. 2t, 172

25. Bordbar. A. K: Moosavi-Movahedi. A. A.: Amini. M. K Thernochim .Acta 2003. 400.95 